\title{
A New Theory of the Evolution of the Insects.
}

\author{
By Dr. R. J. Tillyard, F.R.S.
}

A CRITICAL study of the various theories extant concerning the origin and evolution of the insects as a class reveals that there is so far no general agreement amongst biologists on the point at issue. Handlirsch derives them direct from Trilobites. A long line of authors champion the theory of derivation from Crustacea; wellknown exponents of this theory are Hansen, G. H. Carpenter, and Crampton. Versluys would derive them, with all other Arthropoda, from the Onychophora, by way of the Myriopoda, considering both Trilobites and Crustacea as side-branches which took to the sea. The famous Campodea Theory of Brauer is only one of a number of more or less diverging views which would derive the insects more or less directly from some type of Myriopoda.

It is interesting to notice which type is considered the most primitive of all insects, according to these various theories. For Handlirsch, the original insect was a winged Palæodictyopteron which arose somewhere in the Carboniferous; the Thysanura and other supposedly primitive apterous forms are, for him, debased side-branches of an originally winged main stem. For those who would derive insects from Crustacea, the family Machilidæ of the Thysanura is the most primitive type. Those who support the myriopod theory find the closest connexion between the Symphyla on one side and the Campodeidæ on the other.

All the theories so far put forward appear to fail at some critical point. Few entomologists can believe that winged insects preceded the oldest wingless forms ; it is on this point that Handlirsch's theory, so clearly and fascinatingly presented by its talented author, fails to make appeal. The argument on segmentation drives the adherents of an origin from Crustacea to support a fairly highly evolved type of crustacean, somewhere near the lower Malacostraca, as the ancestor of Machilidæ; but such a theory breaks down when put to the test of detailed analysis. The old crux of the position of the genital pore still stands unsurmounted by those who would like to derive the Campodeidæ from the Symphyla. There is, in fact, no generally acceptable theory as yet.

Where nobody has succeeded, it would seem indeed rash for anyone to make a further attempt. I have, however, done so, not so much with the hope of convincing everybody that I have found the solution, as with the desire to stimulate new lines of thought on a very old problem.*

The theory is built up from the results of an analysis of the evolution of $(a)$ segmentation, $(b)$ the walking leg, and $(c)$ the reproductive system, in insects and other arthropods. As the results ob-

* The complete new theory may be read under the title "The Evolution of the Class Insecta " (Papers and Proceedings of the Royal Society of Tasmania, 1930), which is an amplification of a presidential address on the same subject given in Brisbane in May last, before Section $D$ of the Australasian Association for the Advancement of Science.

No. 3191, VoL. 126] tained from all three analyses were found to agree quite closely, the general theory so constructed was then applied to the evolution of other organs, including the various internal systems, and also to the embryology, with the result that it appears to stand the tests quite well. It also does no violence to the geological record.

In segmentation, attention may be directed to the existence of a nauplius larva in the more primitive types of Crustacea, and to the 'telescoping ' of this larval type into the embryology, in certain specialised types such as crayfishes and syncarids. The conclusion is drawn that the Crustacea are derived from a nauplioid ancestor, though not from any actual type of nauplius. This would imply an original lesser amount of segmentation both in the head and in the body of the animal. As regards the head, the suggestion arises, by comparison of the nauplius head with that of Peripatus, that it was originally only four-segmented, and that the mouth was originally closed behind by a flap or process which was not formed from segmental appendages, but was merely a process of the mandibular segment. From this arose the paragnaths in Crustacea and the hypopharynx and maxillulæ or superlinguæ of insects. The addition of either one or two maxillary segments to the head gave rise to all the five- or six-segmented heads now found in Myriopoda, Insecta, Crustacea, etc.

Turning next to segmentation in the Myriopoda, we meet the phenomenon of anamorphosis, or the addition of segments during ontogeny by interpolation in front of the anal or preanal segment. Such addition may take place either singly or in groups. The young larva hatches out with relatively few body segments, and at each instar there is an increase by anamorphosis, until the full number is reached. An analysis of the ontogeny of the primitive myriopod group Pauropoda shows that the young hatch out with only six postcephalic segments, of which only the second, third, and fourth carry legs. This is the 'six-legged larva'. It is followed by a ten-legged larval stage, a twelvelegged stage, and a sixteen-legged stage, while the adult pauropod has twelve postcephalic segments and nine pairs of legs. Emphasis is laid on the fact that the total segmentation of the pauropod; inclusive of its five head segments, is less than the total of twenty-one or twenty-two required to derive a machilid direct from a lower malacostracan or a leptostracan.

While all Progoneata appear to be anamorphic, and also many Opisthogoneata, there are also certain higher chilopods which, like the crayfishes, have telescoped all their larval segmentation stages into the egg, and hatch out with the fall number of segments belonging to the adult. This phenomenon is termed epimorphosis. It is clear that epimorphic forms are, in this respect, more advanced than anamorphic ones. 
When we turn to the insects, we find that almost all of them are epimorphic, namely, the whole of the Thysanura and Pterygota. One small group, the Protura, still exists which exhibits anamorphosis; the larval form has nine abdominal segments, and three more are added just in front of the last, in the form of ring-segments, before the adult stage is reached.

This analysis now brings us to a hitherto neglected group, the Collembola or springtails. These differ from all other insects in having only six abdominal segments right through their embryology, their larval stages, and the adult. A close comparison can be made between this condition, which is really that of possessing nine postcephalic segments, and the twelve-legged larvæ of Pauropoda and Symphyla. It is suggested that this condition is even more primitive than that of the anamorphic groups, and should be distinguished as protomorphic.

We thus have three stages of evolution in segmentation of terrestrial arthropods: (1) Protomorphism, in which an original small number of segments is retained throughout the ontogeny ; (2) anamorphism, in which this original number is raised, bit by bit, by addition of new segments near the hinder end at ecdysis ; and (3) epimorphism, in which all this larval addition is telescoped into the embryonic period, so that the young larva hatches out with the full number of segments. The Collembola are claimed to be a remnant of the original protomorphic ancestors or Protaptera; but for the fact that their $a b$ dominal appendages have been specialised to serve another function, that of jumping, instead of remaining as walking-legs, they could be classed as very primitive opisthogoneate myriopods. The Protura are a remnant of the later developed anamorphic groups of hexapods. The Thysanura must have begun as Entotrophica and later become more vigorous and developed exserted mouth-parts. The Pterygota or winged insects must have sprung direct from a dorso-ventrally flattened lepismatoid type.

The analysis of the walking-leg brings out two points. First, that there is no evidence of an undoubted exopodite in the legs or maxillæ of terrestrial arthropods, and therefore no need to derive insects from marine forms. Secondly, that the most primitive walking-legs are those of the Symphyla and Collembola, both of which are only actually four-segmented, ending in a claw and empodium.
The abdominal styles and exsertile vesicles of the Thysanura are homologous with those of the Symphyla, both belonging to the subcoxal region. The legs of Collembola are even more primitive than those of Symphyla in not possessing either of these organs and also in the non-development of any definite scheme of chitinisation of the subcoxal region.

The evolution of the leg in Myriopoda may be followed out through stages with six, seven, and

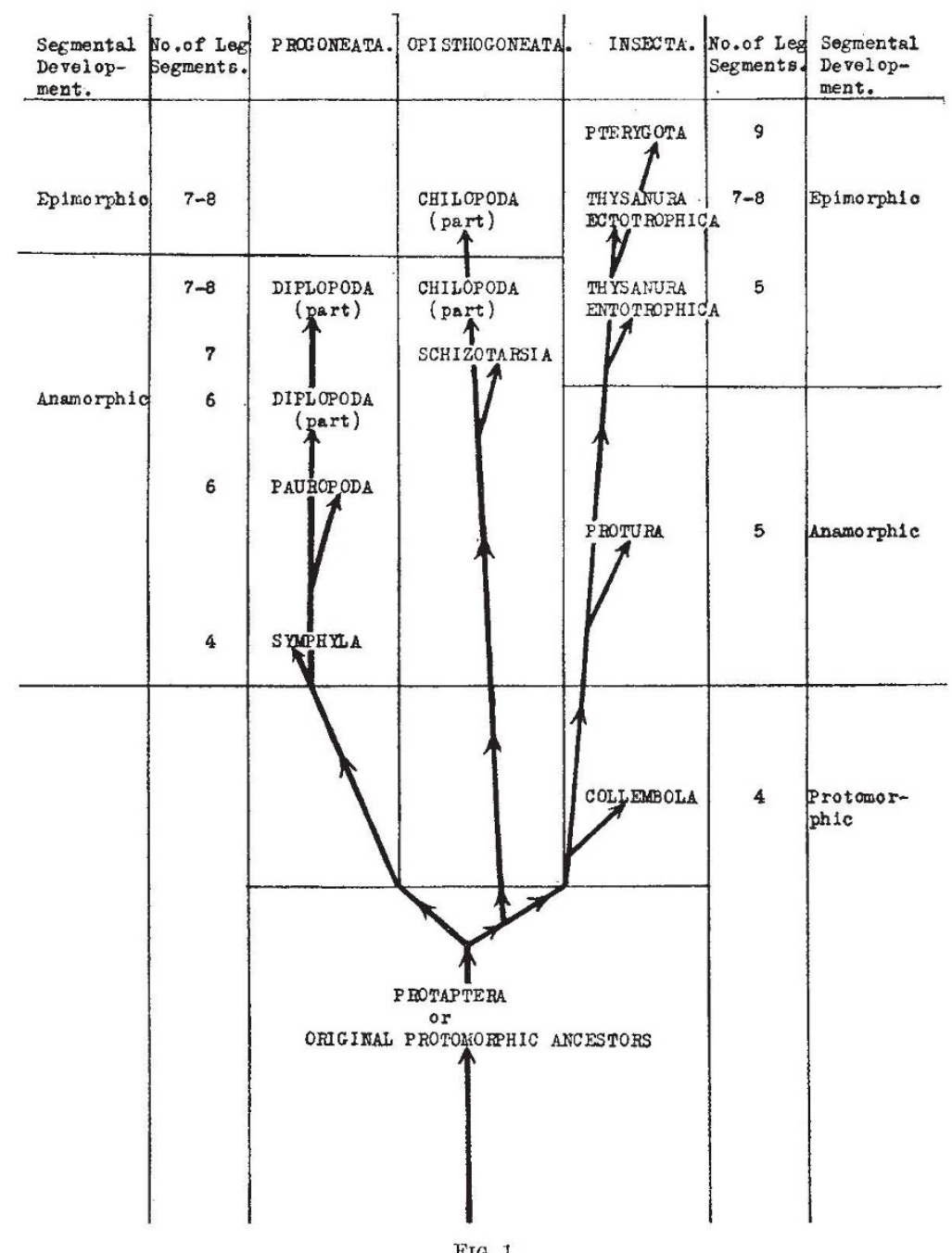

eight segments, that of insects through stages with five, seven, eight, and nine segments, the latter being the types having a tarsus with five divisions. The additional subdivisions do not take place similarly in myriopods and insects, and hence it is not allowable to homologise the separate segments above the original four in the two types.

Coming next to the crux of the reproductive system, and dealing first with the Japygidæ and the primitive Pterygota, we are led to the conclusion that the Thysanura-Pterygota line originally possessed eight pairs of gonads segmentally arranged, of which one pair has been lost in the 
Japygidæ. Counting thoracic and abdominal segments all as postcephalic, the most posterior position of the gonopores in Progoneate types is the fourth postcephalic segment, while the most anterior position in Opisthogoneate types is actually the eighth, in Collembola. Thus both types can be simply derived from an original ancestor which possessed only five pairs of gonads, in the fourth to eighth postcephalic segments respectively. These must be conceived of as having originally opened segmentally by paired gonopores. The linking up of the gonads on each side by paired gonoducts, to open into the fourth postcephalic segment only, gave the primitive progoneate condition, while a similar linking, with backward opening into the eighth, gave the primitive opisthogoneate condition, as in Collembola.

The conclusions arrived at by the above three lines of analysis are so closely similar that it is possible to exhibit them all in a single phyletic diagram (Fig. 1). The original common ancestor of myriopods and insects must have differed from the Onychophora in not being epimorphic and in having fewer body segments. This common ancestor, the Protaptera, would have merited the status of a class. It divided, first of all, into progoneate and opisthogoneate forms ; and, very soon after, the opisthogoneate types divided into Myriopoda Opisthogoneata and true Insecta or Hexapoda. The Collembola are the only remaining remnant of all the ancient protomorphic types. They were quite well developed in the Lower Devonian. The progoneate types culminated in the higher diplopods, leaving the pauropods on one hand and the Symphyla on the other as lowly anamorphic types. The opisthogoneate myriopods ran out into the higher Chilipoda, which are epimorphic ; but, while still anamorphic, they gave rise to another highly evolved type, the Schizotarsia, with annulate legs and large compound eyes. The hexapod or insect line, leaving the Collembola and Protura far behind as lowly side-branches, ran rapidly through the Thysanura Entotrophica to the Thysanura Ectotrophica, and so to the winged forms of Pterygota, probably somewhere in the Carboniferous.

The probable geological horizon of the hypothetical ancestral Protaptera is Upper Silurian, and their ecology is that of terrestrial forms dwelling in moist places and feeding on primitive plant life.

\section{Progress in Education and Research in Agriculture and Fisheries.}

$\mathrm{I}^{\mathrm{N}}$ NCREASING recognition is being given to the fact that many problems connected with agriculture need the help of the trained research worker as well as that of the practical man. During the last twenty years, since the appointment of the Development Commission, steady and rapid progress has been made, until at the present time the ramifications of the system of research and advisory work set up by that body extend over a surprising variety of problems. Three reports recently issued, one by the Development Commissioners, and two by the Ministry of Agriculture on agricultural research institutes and research and education respectively, present a comprehensive picture of the existing state of affairs in Great Britain.

The report of the Development Commission* falls into four sections, the first two of which relate to the grants which have been recommended for the development of agriculture, rural economy, fisheries, and harbours, and describe the purposes for which these advances are being used. The third part of the report relates to action taken under Part 2 of the Act of 1909 in connexion with the compulsory acquisition of land for road improvements. The fourth part deals with the financial position of the Development Fund at the end of the year 1929-30. The advances recommended from the fund amounted to $£ 721,653$, as against $£ 394,752$ in the previous year. The large increase for agriculture and fisheries is attributable to recommendations for capital expenditure out of a special grant of $£ 500,000$ made for unemployment relief. Schemes relating to fishery harbours and

* Development Commission. Twentieth Report of the Development Commissioners, being for the Year ended the 31st March 1930 Pp. 247. (London: H.M. Stationery Office, 1930.) 3s. 6d. net. reclamation are receiving special attention, and any economic schemes of reclamation which may be put forward will receive favourable consideration.

Among the activities of the Commission, those dealing with the development of the countryside make a wide appeal. Rural industries are being aided and developed in thirteen counties by means of grants to be expended according to local needs for the organisation of classes and the staging of exhibits at shows. Some counties now have permanent showrooms for exhibiting craftsmen's goods. The building of village halls is much encouraged by a system of loans which has now been thrown open to the whole country by the establishment of ad hoc committees in counties not having a community council. The success of the scheme is such that in the first three months of 1929,279 villages made inquiries as to loans, and during that period fourteen loans, amounting in all to $£ 3833$, were approved.

Another feature of the year's work of the Development Commission has been the adoption of methods for the relief of the fishing industry by remission of debts and by reconditioning of harbours with the view of the development of fisheries. A total sum of $£ 34,770$ was recommended during 1929-30 for the maintenance of fishery research. The grants are for 'directed ' researches, deliberately planned to find a solution of problems affecting the commercial fisheries, and 'free' researches, the object of which is to advance that knowledge of marine life in relation to its whole environment upon which the solution of practical problems ultimately depends. The fisheries section of the report sets forth much interesting information, and is calculated to surprise the average reader by the

No. 3191, VoL. 126] 